\title{
Creating value for Small and Medium Enterprises with the logistic applications of blockchain
}

\author{
Klara Paardenkooper \\ Knowledge Center Sustainable PortCity \\ Rotterdam University of applied sciences \\ Rotterdam, The Netherlands \\ K.M.Paardenkooper@hr.nl
}

\begin{abstract}
Blockchain is a new technical innovation based on distributed ledger technology, which, according to the literature, promises to improve supply chains by facilitating trusted transactions. Due to its immutability it can help eliminate third parties, which traditionally intermediate between the parties involved in transactions. Large multinational companies that have major influence in supply chains can easily rape the benefits of blockchain, however, small and medium size enterprises (SMEs), which together generate 99\% of the added value of the Dutch economics, do not have the means to achieve this. Therefore, this research poses the question, which user cases exist already and which opportunities do they offer for SME's to create value. The paper answers this question based on literature and the analysis of 70 user cases. Based on the analysis the SMEs are advised, which of the following five strategies to follow, ignoring it, waiting to see the market developments, make use of blockchain services offered by the new blockchain based middlemen, such as the supply chain finance, paperless and market platform solutions, integrate in existing blockchains of multinationals as Maersk or create their own blockchain.
\end{abstract}

Key words- blockchain, logistics, supply chain, technology innovation, transactions

\section{INTRODUCTION}

Blockchain is a distributed database of transactions based on Distributed Ledger Technology (DLT). It is a system that can facilitate trusted transaction including automated payments as it is secure, immutable and smart contacts can be included in it. According to the literature it has a potential to circumvent using middlemen, such as banks, notaries and forwarders as the trust that these parties supply is transferred to the code, which is free of intentional or unintentional human errors. Blockchain is a disruptive technology for logistic processes as it facilitates direct decentral transactions between parties in the supply chain, without the traditional cooperation of trusted third parties. (Casino, Dasaklis, \& Patsakis, 2019) Trust in intermediaries is replaced by trust in the program code and consensus rules, including smart contracts, which make well applied blockchains safe. (Capgemini, 2018) Blockchain has numerous applications, in health, education, privacy and security, business and industry, data management, finance, integrity verification, governance and internet of things. (Casino, Dasaklis, \& Patsakis, 2019). In spite of the fact that it is a relatively new technology, in the literature there is a consensus about the prospects of blockchain technology to make logistic processes more efficient. For example, for port applications it can be used for cargo documentation transactions, substituting the paper flows, in combination with Internet of Things applications for process traceability, for trade finance and again in combination with Internet of Things.
Technology combined with Smart Contracts for automatization of processes. (Francisconi, 2017)

Kshetri (2018) identifies the benefits of the application of blockchain in the supply chain as costs, speed, dependability, risk reduction, sustainability and flexibility. (Kshetri, 2018) This potential of blockchain has been recognized by major stakeholders in supply chains, such as Maersk and Kuehne and Nagel. These parties often control extensive door-to-door logistic processes and have the financial means for reaping the advantages of the application. However, SME's, which often act as intermediaries and thus their business model is endangered by blockchain, do not have these advantages. (Beije, 2016) This paper explores how SME's still can create value, using the logistic applications of blockchain.

The Dutch Economy relies heavily on Small and Medium Enterprizes, (SME's). 99\% of the Dutch companies are SME's and together they produce $60 \%$ of the added value of the Dutch Economy. $61 \%$ of the revenues of Dutch SME's are generated by commerce, transport and warehousing (Staatvanhetmkb, 2019) The SME's in the logistics sector are often traditional in their way of conducting business. Obviously, the new trends digitalization and automation can form a major challenge to them. Contrary to major companies, such as Maersk and Amazon, who have the means to react promptly and benefit from the new technologies, most SME's miss the manpower, skills and knowledge to follow the trends themselves. The questions of the companies are quite similar: What is blockchain? What are the consequences of blockchain for their business model? What kind of knowledge should they have about the potential of blockchain? What does it mean for their business model and processes, if powerful companies, which have major power in supply chain management, implement blockchain? Can the implementation of blockchain technology push them out of the market? Could blockchain technology improve their logistic processes? How can blockchain technology create added value for their company? Is it possible to create the same added value using an alternative technology? In case blockchain actually can generate added value, how to implement it?

In this paper the preliminary results of a research on the subject are presented. The research has an applied perspective, it is deductive, meaning that it uses theoretical insights to improve the practice. The multiple case study strategy of the analysis does apply induction, however the research does not have an ambition to create theory, rather to give practical advice to companies in the logistics field. The central research question of the paper is, which user cases exist already and which opportunities do they offer for SME's to create value. After an introduction to blockchain and a review of the most important literature that the paper builds on, the methodology 
of the case selection the analysis is explained followed by the analysis of the user cases themselves. The paper concludes with an answer to the central research question and a prliminary advise to SMEs. based on the results of the preliminary research.

\section{THE CURRENT STATUS OF THE TECHNOLOGY}

Blockchain is a part of the triangle which also includes Artificial Intelligence and Internet of Things, all creating and using Big Data, a major technological development in the $21 \mathrm{st}$ century. These innovations, also called Data Driven Logistics, have a huge potential to improve supply chains. According to Furlonger and Kandaswamy (2018) blockchain fits into a timeline which started in the 1990's with the Internet of Information, followed by a transition in the 2010's to an Internet of Content. Blockchain is expected to develop further into and interoperable Internet of Value. It is even predicted that it will eventually lead to a programmable economic and societal model after 2026. (Furlonger \& Kandaswamy, 2018) However, at the moment according to the Gartner Hype Cycle of emerging technologies (Fig. 1) Blockchain is situated at the hype of inflated expectations, which means, according to Gartner, that it will probably take 5 to 8 years until the technology will be applied on a large scale. On the curve it is approaching the through of disillusionment, which is supported by the negative publicity that it has received lately. (Gartner Hype Cycle, 2018) A report of Capgemini (2018) enforces this. According to this report in 2018 the majority $(87 \%)$ of the Blockchain projects were no more than proofs of concepts (Capgemini, 2018)

As mentioned above, blockchain is a distributed ledge secured by cryptography. Blockchains can be public or private, permissioned or permissionless. The best known example of a public blockchain is Bitcoin and other cryptocurrencies. Public applications are open and can be used by millions of participants. In order to keep the transactions secure, an enormous amount of algorithms need to be calculated. This is done by the so called miners, who offer computing capacity for rewards. (Pilkington, 2017) Private applications involve less participants. Consequently, the transactions are less complicated and there are no minors needed to help execute them. For logistics applications the private permissioned systems are used most often, however open systems are expected to be used in the future. (Dutch Blockchain Coalition, 2019)

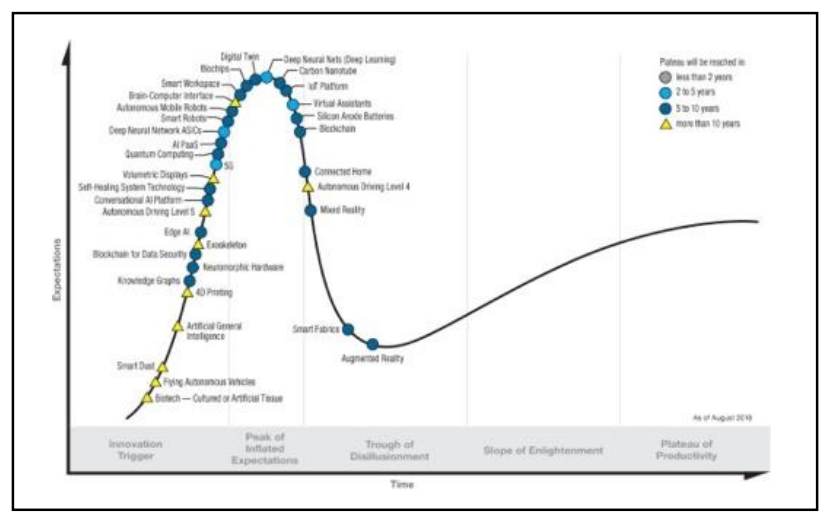

Fig. 1 Gartner's hype cycle of emerging technologies Source: (https:// www.gartner.com/smarterwithgartner/top-trends-from-gartner-hypecycle-for-digital-government-technology-2018/, sd)

\section{METHODOLOGY}

The core of this paper is formed by an analysis of 70 user cases of Blockchain. It builds forth on a previous publication, (Paardenkooper, 2019), however, here the number of cases are extended and some new evaluation criteria are added, this way creating more breadth and depths to the analysis. In this section the source of the cases, the selection criteria, and the analysis method are described. The cases are mostly found in logistic publications and all available cases were included within the available time. The information from the publications was verified by consulting the companies' websites. During the collection and verification, the possible commercial purposes there were taken into account, in order to prevent bias. For the selection of the cases a cross sectional method is chosen. As there are a limited number of user cases, the cases are heterogeneous, small and large scale in different stages of application, both pilots and proven cases of functioning applications. The reason for this choice was to build on the work of Kshetri (2018) involving a substantially broader analysis. Because of the diversity of the cases some attributes were involved in order to be able to make distinction in the heterogeneous material. During the analysis it turned out that extra criteria were needed, such as tokenization, which did not seem relevant in the beginning. The involved attributes are firstly the country of origin, to see which are the specific Dutch applications, secondly the scale of the operations, to examine, how relevant the application is for the scale of activities of the Dutch SME's. Thirdly, the industry where they are applied in order to gain knowledge on where the business opportunities lie. Fourthly, the use of the application is addressed to see the purpose for which they are intended. Fifthly, an estimation was made whether there was a platform or a network applied. Finally, this aspect did not seem to deliver added value, so it might have been as well omitted. Sixthly, a variable, the inclusion of which did supply valuable result is a distinction between supply and demand. Supply means that a company offers blockchain services to other parties, while demand means that a logistic party itself has built, or let build and application for its own purposes. The last two elements are whether in the application tokenization is involved or not and whether the company specifically offers services to SME's.

After having included the attributes the cases were analysed to see which benefits of blockchain defined by Kshetri (2018), namely costs, speed, dependability, risk reduction, sustainability and flexibility were exploited by the cases. The cases were validated by focus interviews with SME's where the question was posed whether they can identify not yet mentioned benefits.

\section{ANALYSIS}

In this section the analysis of the 70 user cases is presented. As mentioned above the analysis is partially based on the well cited article of Kshetri. (Kshetri, 2018). Khsetri (2018) explored eleven user cases of blockchain applications. The applications he discusses are mostly meant for food security, the tracking of meat, fish, coffee and quality wine. Furthermore, he mentions the well-known Maersk case, which creates efficiency by digitalizing and putting the paperwork of transport documents in the blockchain. Two companies are involved in the cooling of medicine andthere is one company that uses the advantages of Blockchain for 
securing 3D print patterns of parts of military equipment. In these cases the companies benefit from the following attributes of blockchain: the time stamp, the trusted storage of documents, the trustworthiness of information. Based on this cases, Khsetri identifies the benefit of the application of blockchain in the supply chain as costs, speed, dependability, risk reduction, sustainability and flexibility. Most of these companies were major players in the United States or the global world. Only some of the cases were small startups and there were only two European cases. The 70 cases that are used for this paper are more diverse, both geographically and in the industry that they are active in.

Here, the cases are firstly analyzed according to the attributes: country, scale, industry, use, network/platform, supply/demand, tokenization and whether they specifically target SME's. Firstly the country of origin of the cases is mostly European. The Jordanian case is related to refugee camps, thee Singapore case is a local sharing platform. The German and the French cases are related to the car industry and de Swiss case to Pharmaceuticals. The Anglo-Saxon case are, opposed to Kshetri's article in the minority. The reason for the majority of the Dutch cases is the availability of the cases caused by the language. The relatively large number of cases (14) identified as international is caused by the fast that 50 of the companies are multinationals. Fig. 2 supplies an overview of the countries of origin of the cases. Fig. 3 shows the scale of activities of the cases. Here global activities form almost the half of the user cases. This could be explained by a commercial factor, a lot of Dutch companies advertise their activities as global on their websites. The division of the countries and the activities in general can be explained by the division of the size of the companies. As mentioned above 50 of them are multinationals, 15 nationals and there are only 4 SME's.

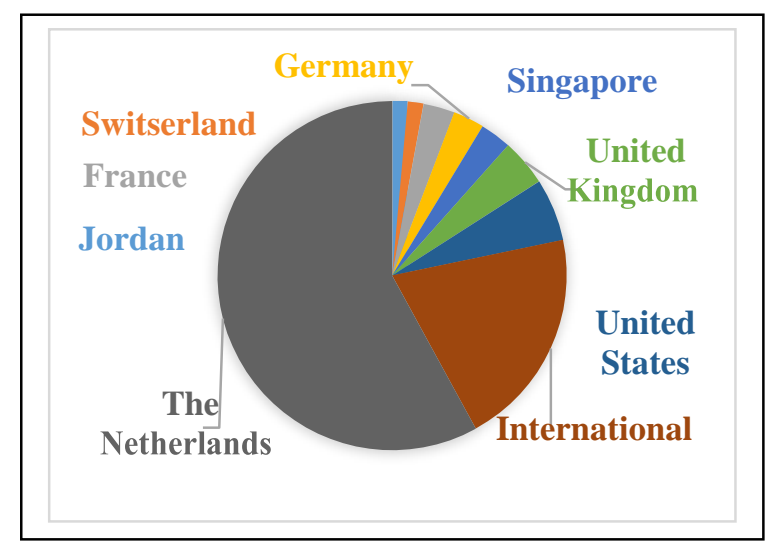

Fig. 2 The country of origin of the cases

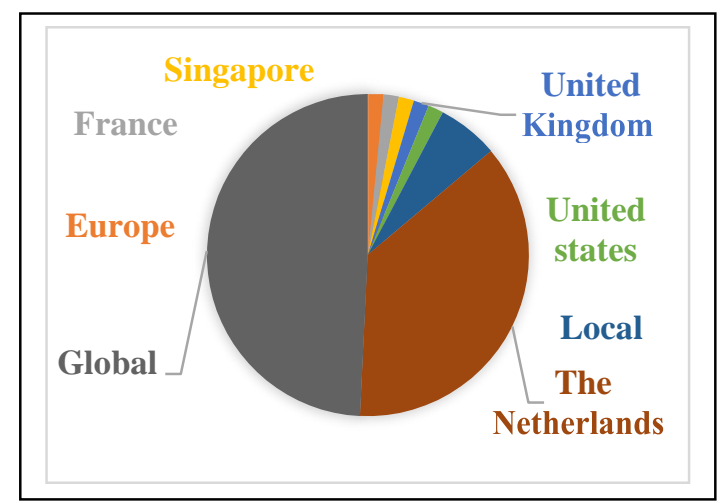

Fig. 3 The scale of activities of the involved countries

The industry of the cases is diverse, as could be expected based on the work of Casino et. al. (Casino, Dasaklis, \& Patsakis, 2019) varying from the automobile and aerospace industry to clothing and humanitarian. The most important three industries are finance, food and transport. The financial user cases are connected to supply chain finance applications, the food sector to food safety and the transport sector mostly to paperless applications and communication platforms. The transport sector traditionally generates major paper flows, as there are numerous parties are involved in a transport of a singular cargo unit and miscommunication often generates inefficiencies. Fig. 4 gives an overview of the industries of the cases. The use of blockchain varies from compatibility to payments. The three top applications are paperless, transactions and tracking. Paperless applications are as mentioned above especially for the transport sector. Transactions means different platforms, which make it possible for partners to exchange information of do business in a secure way. Tracking refers to traceability services and the proof of origin and the quality of products. Both of these would be possible using different applications, however, blockchain offers data, which is immutable. This could be important as the parties involved in sector have an incentive to change the data. Fig. 5 shows the use of blockchain in the cases.

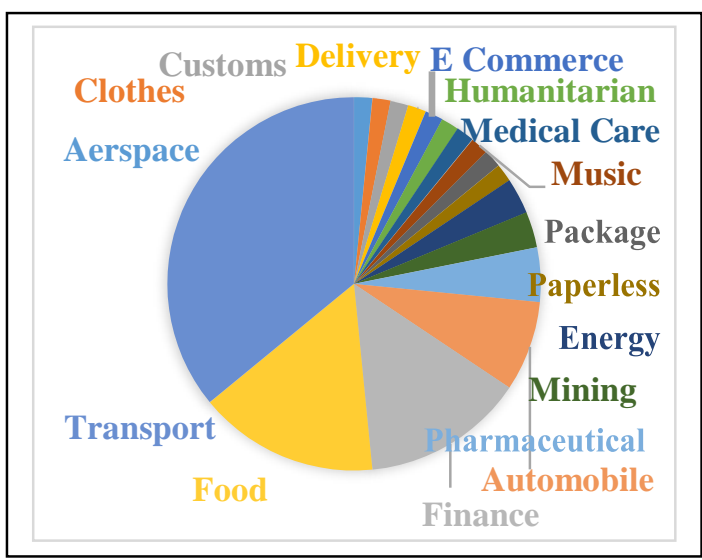

Fig. 4 The Industries of the cases 


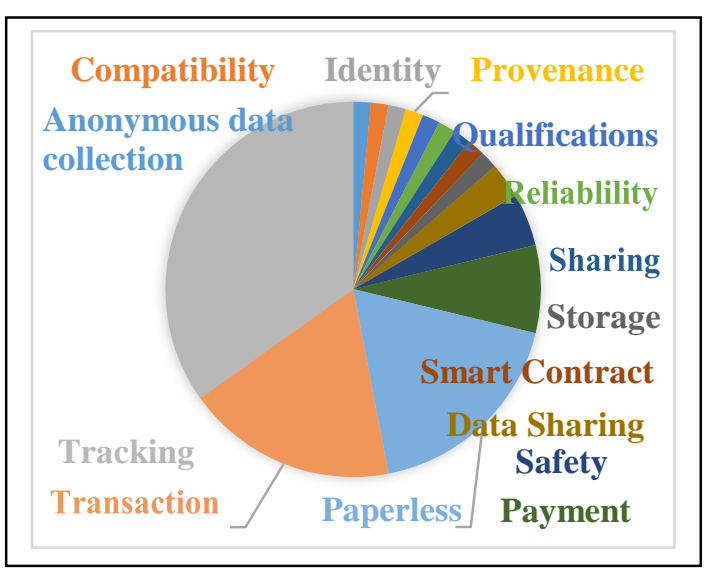

Fig. 5 The use of blockchain in the cases

The analysis on whether a network or a platform is used, shows, that in 28 cases a platform is used is used and in the rest of the cases a network. A platform is used for information exchange and the facilitation of trusted transactions, a network is applied for example for tracking. As mentioned above, inserting this factor did not deliver useful insights. In 3 there cases tokenization is involved. This means that within the blockchain incentives are offered to stimulate the parties involved to desired behavior.

The division into supply and demand, however, does lead to important results. The analysis shows that in 40 cases the application of blockchain was driven by demand, meaning that a company's problem is solved by implementing blockchain, while in the rest of the cases a party offers blockchain solutions on the market. It is interesting to explore these cases further as according to the literature blockchain can eliminate the middle men, the trusted third party in the market. However, it seems that it also means the emergence of a new sort of middlemen, the one, providing a blockchain solution.

Out of the 40 cases 30 offer a service that is relevant for Dutch SME's. 14 of them are transport services, tracking, safety, reliability, data sharing, paperless, financing, and payments. Tracking, safety and reliability services could add value by risk reduction, data sharing could help in consolidation, paperless could make the data flows more efficient and sustainable. Finally, financing and payment services are peculiar, as the payments still go through banks. This way, these services do not circumvent the financial trusted third party, but add a new one.

7 cases offer specific financial services such as payments and transaction including invoicing. These cases are equally intriguing, as the internal ICT systems of companies are supposed to be able to provide this service. Obviously, in these cases the parties offering the service exploit inefficiencies of internal systems of companies. In this case it is questionable whether these companies should look for a solution outside of their walls. 3 companies offer ICT solutions, these are the ones that could build blockchains for the company's needs. 2 offer paperless services and 2 tracking applications for the pharmaceutical industry. Finally, there is an interesting application in Singapore, which is used for the sharing of mailboxes for deliveries. This could be an example for sharing applications for SME's. In order to focus more, here the 6 user cases that concentrate specifically on SME's are described. These are all Dutch cases, so they should be fitting and available for the Dutch SME's. these are Boozt24, Voordegroei, Transfollow, Factris, Cargoledger and Validaide. Firstly the 3 supply chain finance cases, Boozt24, Voordegroei and Factris are discussed.

The first of the supply chain finance cases, Boozt24 is a fintech company, a spin-off of the ING bank, but it is not a bank itself. It finances the invoices of SME's with the minimum turnover of 250.000 Euros per year. Regular banks are compelled to charge high interest for SME's as they are considered risk full investments by thee regulator. However, Boozt24 can keep thee interest low as it uses up to date data of the invoices and that was can assess the risks better than a bank that regularly works with old data. Boozt 24 has relatively low percentages of clients from the transport sector, as this branch is not well acquainted with fintech applications. However, the company has an ambition to be more involved in the sector as it aims to start a supply chain community, which could share the risks and this way push the interest rate even lower. (Baalen $\&$ Heunks, 2017) The second supply chain finance application is Voordegroei a crowdfunding platform with a similar role as Boozt24, the financing of SMEs. It is an online platform that matches SMEs with investors. The company itself does the quality check and the risk assessment. It targets the top segment of SMEs and issues credits above 250.000 Euros. (Spelier, 2016) The third supply chain finance case is Factris a financial innovation, a platform that provides financing for companies by buying up their open invoices for an interest starting from $0,5 \%$. It is surprising that in spite offering a blockchain platform it advertising with personal service. (Factris, 2018) These 3 financial applications of blockchain are new opportunities for SME's to get financing as getting loans from a bank is quite difficult for them. These financial innovations are not well known for SME's, however, this is one of the new chances that blockchain can offer them, just as paperless solutions, which are discussed in the next section.

There are two user cases, which offer paperless solutions for SMEs, Transfollow and CargoLedger. Transfollow is a neutral platform initiated by EVOFenedex, the Dutch professional organization of schippers and TLN, that of road haulers and it is a platform that facilitates the digital CMR, the bill of lading for road haulage. CMR stands for Convention Relative au Contrat de Transport International de Marchandises par Route and it is a main cause of paperwork for the sector. Transfollow supplies an Application Programing Interface (API) for programmers to implement at road transport companies. This way the participants of the supply chain can access the CMR document easily. The digital CMR is highly standardized and it is being rolled out internationally in cooperation with the International Road Transport Union. The advantages of implementing the digital CMR according to Transfollow are planning optimization caused by the transparency of the data, less paperwork, and easy quality control. The system has been adopted by 10 parties and 17 parties are busy implementing it. One of these parties is the ABN Amro Bank supply chain project. (Transfollow, 2019) The second paperless solution, CargoLedger is a spinoff of the World Port Accelerator and it offers a digital CMR, just as Transfollow, however, it also supplies track and trace services. According to the website it is possible to spare at least 5,33 
Euro per digitalized CMR document, especially by less validation and verification. Cargoledger promises that its application is compatible with existing ICT systems, it just and a layer to it. Surprisingly enough Cargoledger is an open blockchain based on Hyperledger and in the future possibly it will involve tokenization for rewarding desired consumer behavior. (Cargoledger, 2019) These two paperless applications clearly offer sustainable and cheap solutions for reducing the paperwork and making communication with the supply chain partners of SMEs. Another ways for SMEs to benefit from the new solutions made possible by blockchain.

The last user case mentioned in this section is Validaide a market platform for Air- and high value cargo suppliers of logistic services. Validaide has major ambitions; for buyers offering a secure online platform for data storage and workflow management and for suppliers capability assessment based on a standard capabilities checklist and supplier qualification. Validaide intends to create value for its customers by sparing the costs of the customary risk assessment, while choosing a new supplier. (Validaide, 2019) This application offers third party services, clearly a new middlemen. It creates its business model by offering trust, similarly as Booking com does for accommodation, by supplying evaluation of services.

The analysis of the benefits of blockchain for the companies delivers the following results, displayed at Fig. 6. The most important benefits seem to be dependability and risk reduction. This is hardly unexpected as according to the literature the automation of trust it the major characteristic of blockchain, a tamper free system with the use of time stamps and smart contracts. The fact that costs stay behind is misleading. Costs were included when in the description of the case the financial argument was mentioned. However, the growth of dependability and risk reduction would automatically lead to cost reduction. Sustainability was mentioned explicitly in 26 cases, Notwithstanding eliminating paperwork leads to more environmental friendly practices and so does the increase of efficiency by for example making better use of transport capacity, which leads to the reduction of $\mathrm{CO}_{2}$ emission. Speed can also be increased by efficiency, but it was not mentioned in approximately the half of the cases. The last factor is flexibility, which is hard to derive from the cases, however, it is expected that a good information management would enhance flexibility. The overview of the analysis can be found at Fig. 6.

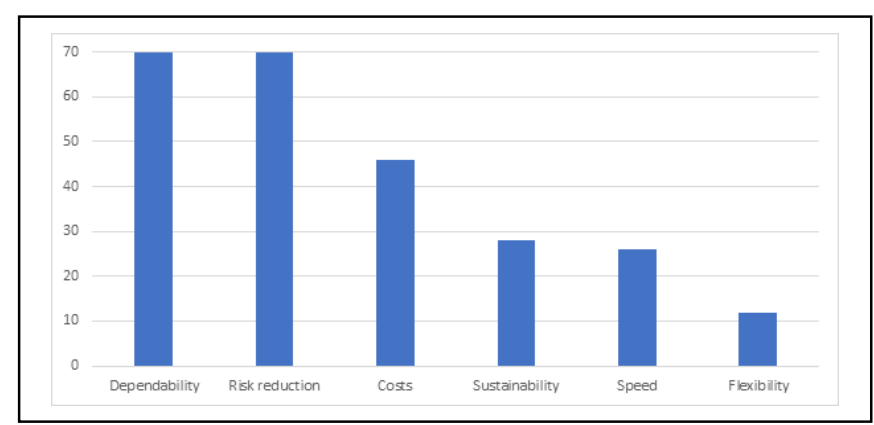

Fig. 6. Benefits of blockchain

\section{CONCLUSION}

Blockchain is an emerging technology which is at the moment going down on the hype cycle on its way to a phase, when it probably will be applied widely, according to Gartner, in 5-8 years. Major parties, which have great influence of the supply chain already have made serious efforts to use blockchain technology to improve their supply chains. It is important for SME's to see what kind of consequences the fact that these companies embrace blockchain has for their business models and how they can add value by using this application themselves. This paper presents the preliminary findings of the project. The central research question of the paper is, which user cases exist already and which opportunities do they offer for SME's to create value. In the paper the question is answered by the combination of literature and an analysis of 70 user cases, in different industries. The user cases are analyzed based on the factors, country of origin, scale of operations, industry, purpose, whether it is a platform or a network, whether it is related to supply or demand, whether it is offered specifically to SMEs and the factors shown by costs, speed, dependability, risk reduction, sustainability and flexibility.

The research has shown that the solutions are offered in transport, data sharing, paperwork eliminating and tracking applications and supply chain finance solutions. Almost the half of the user cases were formed by parties, which offer blockchain based services. These are new middlemen. The literature and the analysis both show that blockchain is a possible solution for problems involving trust issues and it can help eliminating trusted third parties, such as customs, insurance, inspectors, a bank or a debt collector. However, this research indicated that the middlemen are in many cases not eliminated, but being replaced by others. The analysis has also shown that dependability and risk reduction are the most common and most important attributes, that finally influences the cost factor. Costs and speed played a less important role, followed by sustainability and flexibility, which appeared to have minor influence. These attributes can be used for SME's as KPIs to make their processes more efficient by blockchain applications.

Based on the research the following advice can be given to SME's. There are five possible strategies that companies can follow in relation to blockchain. Firstly, ignoring it, it will go away. This strategy is not advisable as the interviews, literature and the case analysis of the cases show that blockchain has a major potential for facilitating trusted transaction by eliminating the middlemen even if it gives a 
chance to new middlemen. Secondly, waiting to see the

market developments. This strategy is more to be advised as according to Gartner it might take a few years until blockchain will be applied on a wide scale and it might be wise to wait how the market reacts. Thirdly, the company could make use of blockchain services offered by the new blockchain based middlemen, such as the supply chain finance, paperless and market platform solutions, in case they offer them advantages. Fourthly, a company could join the blockchain of multinationals, such as Maersk, to integrate in their system. However, the company need to realize that the system is owned by the major player and it does not give much negotiation power to the SME itself. Fifthly, an SME could create its own blockchain, and try to convince its supply chain partners to join it. In that case it is its own blockchain, which gives it a power position if the others are willing to join. This can be done either by making an own blockchain, that requires quite major technical knowledge, or outsource it to a provider.

When considering the application of blockchain the downsides of blockchain need to be taken into consideration. Firstly, the security issue, which is in spite of the fact that because of its encryption is considered a safe system, is a threat on different levels. Secondly, the vicious circle of trust, meaning that in order to create trust between parties using blockchain an initial trust is needed. Thirdly, it should be seriously considered, whether blockchain is the right solution and there is no better ICT solution for the given problem. For this there are diverse frameworks to be used. Further research should look into which applications are interesting to which companies and assess how these examples that are applied at major companies can de downsized to SME's and quantify how much value can be created using the different applications and calculate business models.

\section{ACKNOWLEDGMENT}

This research is funded by NWO SIA RAAK project under the name Blockchain for SME's and is performed by researchers from the Rotterdam and the Windesheim universities of applied sciences in the Netherlands

\section{REFERENCES}

[1] F. Casino, T. K. Dasaklis and C. Patsakis, „A systematic literature review of blockchain-based applications: Current status, classification and open issues," Telematics and Infomatics, pp. 55-81, 2019.

[2] Capgemini, „Does Blockchain hold the key to a newage of supply chain tranparency and trust? How organizations have moved from blockchain hype to reality," Capgemini, 2018.

[3] M. Francisconi, „An explorative study on blockchain technology in,” Delft University of Technology, Delft, 2017.

[4] N. Kshetri, „Blockchain's roles in meeting key supply chain management Objetives," International journal of Information Management, pp. 80-89, 392018.

[5] A. Beije, „A lead via Blockchain technology," City of Rotterdam, Rotterdam, 2016.

[6] D. Furlonger en R. Kandaswamy, „Understanding the Gartner Blockchain Spectrum and the Evolution Technology Solutions," Gartner, 2018.

[7] Gartner Hype Cycle, „https://www.gartner.com/smarterwithgartner/5-trends-emerge-ingartner-hype-cycle-for-emerging-technologies-2018/,", 2018. [Online].

[8] M. Pilkington, „Blockchain Technology: Principles and Applications," 2017.

[9] Dutch Blockchain Coalition, „Blockchain Security A framework of trust and Adoption," DBC, Delft, 2019.

[10] „https:/www.gartner.com/smarterwithgartner/top-trends-fromgartner-hype-cycle-for-digital-governmenttechnology-2018/," [Online]. Available: https://www.gartner.com/ smarterwithgartner/top-trends-from-gartner-hype-cycle-for-digitalgovernment-technology-2018/.

[11] K. Paardenkooper, „Creating value for SME's with logistics applications based on Blockchain," Logistiek, tijdschrift voor de toegepaste logistiek, pp. 58-71, 2019.

[12] P. v. Baalen en M. Heunks, ,Adoption of Fintech Services by SMEs in the Logistic Sector Preliminary Findings," University of Amsterdam, Amsterbam, 2017.

[13] P. Spelier, „Crowdfundingplatform Voordegroei.nl: investeren in topsegment MKB," Emerence Financials, 2016.

[14] Factris, „Factris sluit kredietfaciliteit van €100 miljoen,” 2018. [Online]. Available: https://www.emerce.nl/wire/factris-sluit-kredietfaciliteit-100miljoen.

[15] Transfollow, 2019. [Online]. Available: https://transfollow.org/nl/.

[16] Cargoledger, 2019. [Online]. Available: https://cargoledger.n1/.

[17] Validaide, 2019. [Online]. Available:https://www.validaide.com/. 